\title{
EDITORIAL
}

\section{Precision medicine: precision viticulture}

(c) The Author(s), under exclusive licence to Springer Nature Limited 2022

Bone Marrow Transplantation (2022) 57:695-696; https://doi.org/ 10.1038/s41409-022-01601-0

'The doctor should support the hope of the patient to recover'.

Hippocrates. 460-370 BC.

Greek physician (Fig. 1).

Many of us thought we were practising precision/personalised medicine, that is, taking a careful history of the patient's complaints, including a family history, a full physical examination which usually concluded in a differential or precise diagnosis. Appropriate investigations were ordered in the knowledge that the results rarely provided unexpected information but usually confirmed our diagnosis or helped to narrow the differential diagnostic possibilities. Then, following careful consideration of the patient's age and co-morbidities, an appropriate treatment was carefully explained to the patient, always knowing that the outcome was uncertain, but that we will always 'look after you' to the best of our ability.

However, it seems that now precision/personalised (the terms are commonly used interchangeably) medicine has a totally different meaning. The following is the $\mathrm{NCl}$ definition: Personalised/Precision medicine is a form of medicine that uses information about a person's own genes or proteins to prevent, diagnose, or treat disease. In cancer, personalised medicine uses specific information about a person's tumour to help make a diagnosis, plan treatment, find out how well treatment is working, or prognosticate. Examples of personalised medicine include using targeted therapies to treat specific types of cancer cells, such as HER2-positive breast cancer cells, or using tumour marker testing to help diagnose cancer [1]. The American Society of Hematology has recently provided webinars on identification of somatic and germline variants.

From the haematologist's point of view, the development, use and success of the tyrosine kinase inhibitors in chronic myeloid leukaemia is the most obvious example of precision medicine. Their use has been so successful that compliance is now a problem [2].

When I asked Professor David Nathan what were the most important developments in haematology in his lifetime, he said, among other things, 'the advent of genetics, which changed everything - absolutely everything' [3]. Of course, we now have molecular genetics and the acceptance that cancer is an acquired genetic disorder. The development of Sanger sequencing and now, second-generation sequencing, the completion of the Human Gene project, proselytised by Francis Collins, among others, has yielded myriads of useful information, but has been a little disappointing in terms of human disease and treatment.

Monoclonal antibodies (mAbs) are now widely used and rituximab (anti-CD20) is probably the best known to haematologists. In 1981, the first patient was treated with 'antiidiotype antibodies, truly personalised medicine. However, this approach changed with the development of rituximab against CD20, a target shared by normal B cells and many B cell malignancies [4]. There are many other mAbs, most with unpronounceable names, used in the treatment of a wide spectrum of disorders including infectious diseases, autoimmune disorders and cancer among others. mAbs have been used in the treatment of haematological malignancies, especially nonHodgkin lymphoma (NHL) however, I think it is fair to say that mAbs are usually not curative when used alone but certainly are synergistic when used in combination with chemotherapy. An exception, well known to haematologists, has been the use of eculizumab in the treatment of Paroxysmal Nocturnal Haemoglobinuria.

Gene therapy has been discussed since the 1970s and although we have seen recent strides in the treatment of haemophilia (particularly Factor $1 \mathrm{X}$ deficiency) and sickle cell disease it is unlikely that these types of treatments will be widely used, due to technical difficulties and cost.

Gene editing is very much in vogue in research laboratories and clinical trials are now being performed. It is a very interesting idea although some people look at its application as a form of molecular eugenics.

Personalised medicine is particularly suited to the treatment of haematological malignancies, due in part to the accessibility of the malignant tissue. In many cases, a simple venous blood sample of the malignant cells provides an opportunity for extensive and repeated study whereas in solid tumours a biopsy at the time of diagnosis and perhaps at relapse is all that is available. Tissue banking will help as it makes malignant tissue available for study with evolving techniques.

I was rather surprised, when reading Jancis Robinson recently, to come across the term 'precision viticulture' [5]. She says she came across the term 20 years ago in California but I must confess it was news to me. She claims (and I have no reason to doubt her) that she first came across the term 'precision viticulture' in Napa Valley, in Harlan Estate over 20 years ago. She also says that 'precision viticulture' has been widely adopted all over the world and is de rigueur in Bordeaux. Its rather expensive and time consuming as it means picking grapes by individual parcels and, in some instances, picking them vine by vine. It means that in some instances vineyard teams pass through each vineyard as many as three times per day.

Another technique involves tilling the soil to encourage vine roots to grow deeper in search of water. Most of us are used to see vines in straight lines in well-managed vineyards with little growth, of any kind, between the rows of vines (Fig. 2). However, a number of famous vineyards in Bordeaux are planting hedges and trees to create 'green corridors' to encourage more biodiversity. Some oenologists use modern techniques which utilise GPS for vineyard management activities including vineyard design, vineyard mapping, soil sampling, canopy management, mainly for tasks that required high precision location. 


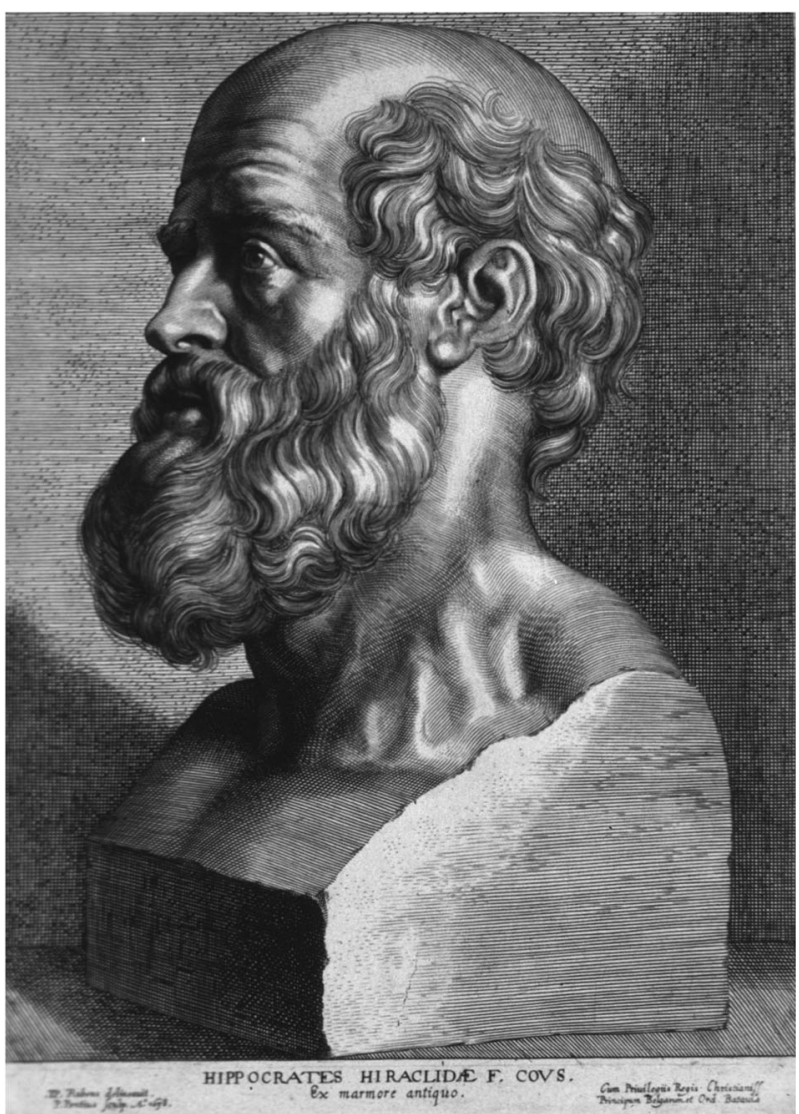

Fig. 1 Hippocrates. Engraving by P. Pontius after Peter Paul Rubens (1577-1640).

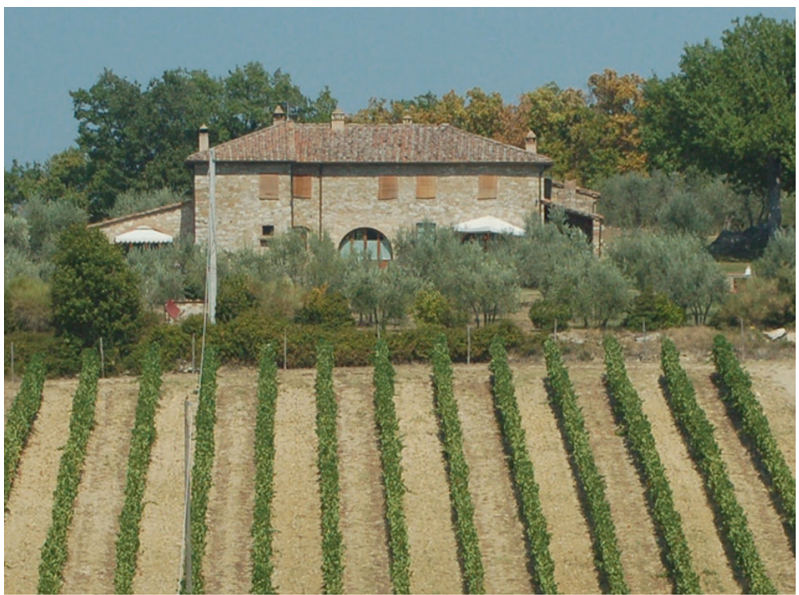

Fig. 2 Tuscan vineyard. Casa Emma, a typical Tuscan vineyard near Radda, Tuscany, Italy. Photograph Brenda McCann.

It all seems a bit futuristic to me. I have made personal contact with a number of oenologists in Tuscany (Fig. 3) and none uses or knows anybody who uses 'precision viticulture'. Perhaps these elaborate techniques will be confined to famous 'high-end' vineyards which produce very expensive wines.

I don't know if 'precision viticulture' makes a difference to the taste of the wine as I rarely drink high-end wines from Bordeaux. Whatever about the technology, find a winemaker you like and

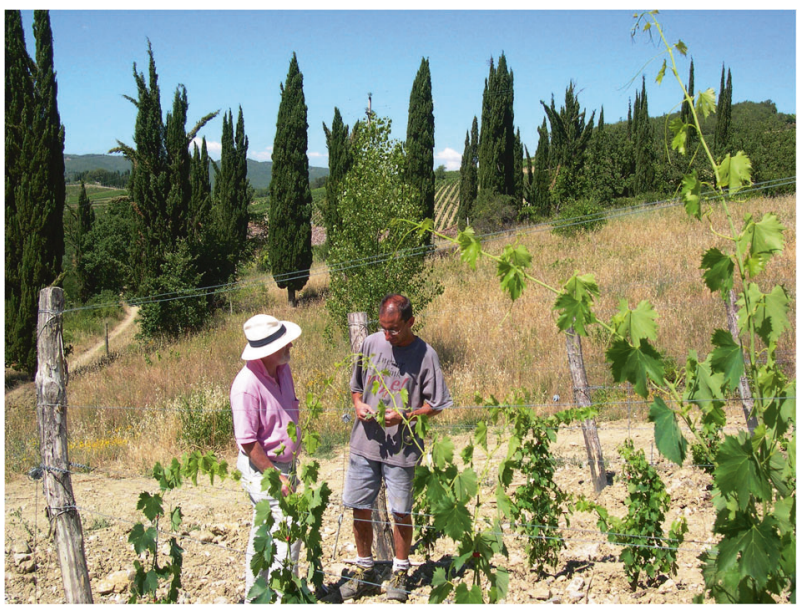

Fig. 3 Poggerino. The author speaking with Piero Lanza, oenologist, Fattoria Poggerino, near Radda in Tuscany. Photograph Brenda McCann.

trust and drink his/her wines. When I am buying wine from a supermarket (and they often have excellent and well-priced wines) I buy one bottle and taste it. If it to my liking I go back quickly and buy a case. If it's really good value the shelf-life can be very short!

Shaun R. McCann $\left(10^{1 凶}\right.$

${ }^{1}$ Bone Marrow Transplantation https://www.nature.com/bmt/.

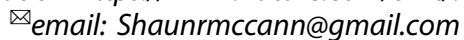

\section{REFERENCES}

1. National Cancer Institute at the National Institutes of Health, Bethesda, Maryland, USA; 2017

2. Marin D, Bazeos A, Mahon F-X, Eliasson L, Milojkovic D, Bua M, et al. Adherence is the critical factor for achieving molecular response in patients with chronic myeloid leukaemia who achieve complete cytogenetic responses on Imatinib. J Clin Oncol. 2010;28:2381-8.

3. McCann SR. Blood matters. Interview with Professor David Nathan, December 2011. European Hematology Association; 2019. ISBN 978-90-823759.

4. 50 years in Hematology. Research that revolutionized patient care. American Society of Hematology; 2008. ash@hematology.org.

5. Robinson J. All change in Bordeaux. 2021. FT.com/Magazine. May 8/9. Financial Times, 1, Friday Street, London, UK.

\section{AUTHOR CONTRIBUTIONS}

All the ideas and writing of this article were by Shaun R. McCann.

\section{COMPETING INTERESTS}

The author declares no competing interests.

\section{ADDITIONAL INFORMATION}

Correspondence and requests for materials should be addressed to Shaun $\mathrm{R}$. McCann.

Reprints and permission information is available at http://www.nature.com/ reprints

Publisher's note Springer Nature remains neutral with regard to jurisdictional claims in published maps and institutional affiliations. 